SANINE, Patricia Rodrigues;

CASTANHEIRA, Elen Rose Lodeiro.

Explorando nexos entre a construção social da criança e as práticas de saúde. História, Ciências, Saúde - Manguinhos, Rio de Janeiro, v.25, n.1, jan.-mar. 2018, p.199-215.

\section{Explorando nexos entre a construção social da criança e as práticas de saúde}

\section{Exploring connections between the social construction of the child and health practices}

\author{
Patricia Rodrigues Sanine \\ Professora, Departamento de Saúde Pública/FMB/Unesp. \\ Botucatu - SP - Brasil \\ elen@fmb.unesp.br

\section{Elen Rose Lodeiro Castanheira} \\ Professora, Departamento de Saúde Pública/FMB/Unesp. \\ Botucatu - SP - Brasil \\ elen@fmb.unesp.br
}

Recebido para publicação em 30.07.2016.

Aprovado para publicação em 12.01.2017.

\section{Resumo}

Busca correlacionar os diferentes significados sociais atribuídos à criança com as ações de saúde dirigidas a esse grupo a partir do século XIX, no Brasil. Ensaio alicerçado em revisão bibliográfica baseada na concepção social do "ser criança" e sua correlação com as políticas e práticas de saúde pública e de assistência à criança, privilegiando-se as ações desenvolvidas no âmbito da atenção primária à saúde. Identificaram-se três diferentes concepções do significado da criança. Exploram-se as inter-relações entre as transformações na construção social de criança e as diferentes proposições políticas e tecnológicas de atenção à criança no Brasil, apontando o desafio contemporâneo de desenvolver tecnologias de cuidado que a fortaleçam como sujeito de direitos.

Palavras-chave: história da saúde pública; saúde da criança; cuidado da criança; história da criança.

\section{Abstract}

This article seeks to correlate the different social meanings attributed to children with health actions directed toward this group starting in nineteenth-century Brazil. The study reviews the literature based on the social concept of "being a child" and its correlation with policies and practices in public health and child care, focusing on actions undertaken within the framework of primary health care. Three different conceptions of the meaning of "child" were identified. The interrelations between transformations in the social construction of the notion of child were investigated, along with the different political and technological proposals involving children in Brazil, indicating the contemporary challenge of developing care technologies that will strengthen children with regard to rights.

Keywords: history of public health; child health; child care; history of the child. 
$P^{\prime}$ ode-se afirmar que a infância é uma etapa do desenvolvimento humano diferencialmente valorizado pelas políticas públicas de saúde. No Brasil, a Constituição Federal refere ser dever do Estado assegurar à criança, com absoluta prioridade, o direito à vida e à saúde (Brasil, 2011), o que ganha expressão no Sistema Único de Saúde (SUS) por meio dos conceitos de integralidade, universalidade e equidade, como princípios que devem orientar ações dirigidas ao desenvolvimento saudável e à prevenção de doenças e agravos na infância (Paim et al., 2011; Victora et al., 2011; Gomes, Adorno, 1990).

A expansão dos serviços, a universalidade das ações e o grau de intervenção social assumido pelas práticas de saúde voltadas para a infância, particularmente via Atenção Primária à Saúde (APS), apontam hoje para a importância de um olhar crítico sobre as ações desenvolvidas, de modo a identificar suas fortalezas e debilidades. Também convidam a analisar a coerência que apresentam em relação ao projeto de saúde socialmente pactuado para esse segmento populacional, como preconizado no Estatuto da Criança e do Adolescente (ECA) e na Política Nacional de Atenção Integral à Saúde da Criança (Pnaisc) (Brasil, 13 jul. 1990, 5 ago. 2015; WHO, 2008).

Os dispositivos de cuidado e proteção à criança, ao lado do próprio significado social do "ser criança", diversificaram-se ao longo da história. No campo da saúde coletiva, o percurso histórico da criança como objeto de práticas sociais tem sido pouco explorado, especialmente quando considerado em relação às práticas dirigidas à infância desde seu reconhecimento como objeto de intervenção em saúde até a recém-promulgada Pnaisc (Brasil, 5 ago. 2015; Schultz, Barros, 2011; Mota, Schraiber, 2009; Zanolli, Merhy, 2001).

Atualmente, a criança é reconhecida em todo o mundo ocidental como portadora de direitos sociais e de proteção especial, garantidos por dispositivos legais socialmente legitimados. Estudos nacionais e internacionais abordam concepções sobre o "ser criança" e suas relações com a dinâmica e estrutura social em diferentes contextos ao longo da história (Cárcamo et al., 2014; Wolfe et al., 2013; Freire, Leony, 2011; Lage, Rosa, 2011; Schultz, Barros, 2011; Lionetti, Miguez, 2010; Mota, Schraiber, 2009; Freitas, 2003; Del Priori, 1991; Fonseca, 1993; Gomes, Adorno, 1990; Ariès, 1981).

Cabe indagar, a partir do reconhecimento da criança como objeto de intervenção em saúde, como as políticas e práticas de saúde pública brasileiras vêm participando desse processo de construção da concepção de infância na contemporaneidade. Em outras palavras, e procurando precisar melhor as indagações colocadas, quer-se trazer para o debate questões como: quais os nexos entre as práticas de higiene e de medicalização da sociedade ocidental e a instituição contemporânea da proteção integral à saúde da criança sustentada como direito constitucional? Como as ações voltadas para a atenção à saúde da criança participam historicamente da construção da concepção de infância como etapa da vida com características e necessidades próprias?

O presente ensaio tem como objetivo discutir alguns dos marcos históricos sobre o modo como a sociedade define a criança e como as diferentes concepções orientam, são apropriadas e reproduzidas nas ações de saúde voltadas para a infância, utilizando como principal cenário de práticas as ações de saúde da criança desenvolvidas no Brasil, particularmente em alguns de seus principais centros urbanos. 
Parte-se do pressuposto de que as práticas de saúde como práticas sociais participam do processo de reprodução social, ou seja, respondem a necessidades e, simultaneamente, integram o processo de instituição de novas necessidades sociais de saúde, reproduzindo tanto valores como mercadorias (Schraiber, Nemes, Mendes-Gonçalves, 2000; MendesGonçalves, 1994; Mendes-Gonçalves, Schraiber, Nemes, 1990; Dalmaso, Schraiber, 1992; Donnangelo, 1975).

Propõe-se uma aproximação do modo como as práticas de saúde têm participado da construção social do "ser criança" e como reproduzem e recriam esse significado à medida que respondem às necessidades sociais desse grupo por meio das tecnologias operadas na atenção à criança. Espera-se que essa abordagem contribua para o fortalecimento de um olhar crítico que favoreça o desenvolvimento de práticas coerente com valores que fortaleçam os direitos sociais e a construção da cidadania a partir da infância.

Trata-se de um ensaio alicerçado em revisão bibliográfica sobre a concepção de criança e sua correlação com as práticas de assistência e de saúde pública voltadas para esse segmento social, privilegiando-se as ações desenvolvidas no âmbito da APS.

A revisão bibliográfica foi realizada nas bases Scopus e Bireme entre 1990 e 2015, abrangendo também a busca de livros e literatura cinzenta - particularmente publicações oficiais do Ministério da Saúde. As teses e dissertações foram excluídas das análises, optandose por trabalhar somente com livros e literatura indexada, com exceção de Sanine (2014), como referência à primeira aproximação dessa temática realizada pelos autores. Foram utilizados os descritores "public health (history)", "child health", "child care", "child health services", "primary health care".

Para seleção dos estudos consideraram-se marcos de inflexão histórica as mudanças na delimitação do "ser criança" como objeto de atenção à saúde; as tecnologias de cuidado voltadas para esse objeto; e a organização dos serviços de atenção à criança, com foco nas ações de saúde e serviços de APS.

O trabalho foi realizado em quatro momentos sequenciais: (1) o material bibliográfico foi separado conforme as concepções de criança, delimitando um primeiro quadro cronológico; (2) as práticas relacionadas à saúde da criança na APS foram formatadas em uma planilha estruturada, num segundo conjunto, destacando: órgão gestor, principais ações e ano de implantação, cujos dados foram organizados em ordem crescente segundo o ano de implantação da ação; (3) foi elaborado um terceiro quadro com as inflexões tecnológicas das práticas de saúde voltadas para criança ao longo dos diferentes períodos históricos; (4) os três conjuntos de dados sistematizados foram sobrepostos delimitando-se como inflexões históricas as mudanças na concepção do "ser criança", procurando-se identificar em cada período alterações na organização e tecnologias de cuidado voltadas para a saúde da criança.

Optou-se por utilizar a expressão "concepção do ser criança" pela sua capacidade de compreender as determinações sociológicas presentes na sua construção e, portanto, evidenciar sua associação com contextos histórico-sociais específicos (Minayo, 1991).

Para delimitar os marcos de inflexões históricas sobre a criança como objeto de atenção, utilizaram como constructo teórico os pressupostos de Schultz e Barros (2011) e Gomes e Adorno (1990), que traçam o desenvolvimento histórico da definição do "ser criança" até 
a compreensão atual, como ser humano em desenvolvimento, constituído como sujeito de direitos e deveres.

Para a análise das diferentes proposições e práticas definidas para os serviços de atenção à criança e das tecnologias de cuidado operadas em cada período, amparou-se na teoria do processo de trabalho em saúde. Segundo esse referencial, as práticas de saúde participam da construção social dos sujeitos, uma vez que, como trabalho, integram o processo de reprodução social (Schraiber, Nemes, Mendes-Gonçalves, 2000, 1992, 1994; Dalmaso, Schraiber, 1992; Mendes-Gonçalves, Schraiber, Nemes, 1990).

Ganham destaque como referências para discussão das ações contemporaneamente voltadas para a saúde da criança no Brasil, os princípios e diretrizes presentes no SUS para a organização da APS; particularmente, para a atenção à saúde da criança, por meio da Política Nacional de Atenção Básica (Brasil, 2012) e da Pnaisc (Brasil, 5 ago. 2015).

A criança enquanto ser social e a própria concepção de saúde são construções históricosociais complexas em constante transformação (Schultz, Barros, 2011; Lionetti, Miguez, 2010; Gomes, Adorno, 1990). Embora as transformações sejam processuais, e diferentes concepções coexistam em sociedades concretas, fez-se um esforço para identificar as mudanças representativas de alterações substantivas na concepção social de criança e de inflexões nas tecnologias e práticas de saúde que integram esse processo.

\section{Construção social do "ser criança"}

No Brasil, a criança não aparece como objeto específico de cuidados ou práticas sociais, nem mesmo como parte das preocupações demográficas, até meados do século XIX, quando a família começa a se organizar em torno da criança, tirando-a do seu antigo anonimato, apesar de ainda manter a concepção restrita ao significado do termo "infante" - aquele que está impossibilitado de falar, que não tem voz no sentido de direito, mas que se encontra em desenvolvimento (Lage, Rosa, 2011; Schultz, Barros, 2011; Santana, Araújo, 2009; Freitas, 2003; Ariès, 1981). Com uma identidade reconhecida e a preocupação em manter a criança saudável para garantir seu pleno desenvolvimento, de modo a atingir a vida adulta sem influências desfavoráveis e problemas trazidos da infância, é que têm início no Brasil as ações destinadas ao cuidado das crianças (Del Ciampo et al., 2006).

Nesse período, emergem as ações de puericultura, ainda constituída por "conselhos de médicos famosos com embasamentos comportamentais e morais" (Campos, Guerrero, 2010, p.352), e as atividades da pediatria, com base nos novos conhecimentos biológicos, podendo ser caracterizada nessa época como fruto "do encontro da puericultura com a clínica de crianças, associando o desenvolvimento e a especificação do corpo infantil, impregnando-se da doutrina de conservação da criança" (Zanolli, Merhy, 2001, p.979).

Caracterizam as práticas dessa época o acompanhamento do desenvolvimento infantil, aleitamento e educação materna, levantamento detalhado sobre as condições em que viviam as crianças desfavorecidas, inspeção nas escolas e vacinação das crianças matriculadas, além de promover concursos (com premiação em dinheiro) dirigidos às mães pobres que apresentassem o bebê mais saudável amamentado no peito (Santos, Resegue, Puccini, 2012; Freire, Leony, 2011; Mota, Schraiber, 2009). 
Assim, pode-se afirmar que a saúde da criança começa a se confirmar, ideologicamente, como um novo campo de investigação técnica e de normatização da vida, que, embora fosse um campo de práticas que desenvolvia orientações amparadas por conhecimentos de base biológica, tinha como núcleo tecnológico principal a educação e como objeto de intervenção ações de caráter essencialmente familiar e comunitário (Freire, 2009, 2014; Freire, Leony, 2011; Campos, Guerrero, 2010; Zanolli, Merhy, 2001; Pereira, 1999; Gomes, Adorno, 1990).

Nessa época, as ações do Estado voltam-se para a infância como meio de implantar hábitos sadios, entendendo a criança como uma "matriz de adulto" que garantiria o futuro produtivo do Estado. Investe-se na medicalização da família por meio da infância, instaurando novas regras sobre as relações entre pais e filhos. Nesse sentido, a criança se mantém essencialmente como objeto de estratégias de ajuste da população ao modelo social como forma de garantir a reprodução da força de trabalho (Freitas, 2003; Gomes, Adorno, 1990; Foucault, 1982; Ariès, 1981).

Observa-se que esse processo, no Brasil, ocorreu de maneira semelhante ao de países como Inglaterra, França, Alemanha e EUA, onde a preocupação com a saúde da criança cresceu conforme aumentava a necessidade de redução da mortalidade nesse grupo como medida para garantir "o aumento da população por meio de homens saudáveis" (Rosen, 1994, p.271).

Na Europa, e posteriormente nos EUA e em alguns países da América Latina, a preocupação com a mortalidade infantil tem expressão crescente desde o final do século XIX, tanto pela necessidade de suprir a reposição de mão de obra como garantir futuros soldados, impulsionando mudanças nas ações voltadas para a criança. A Inglaterra desenvolveu formatos assistenciais inovadores - como visitas domiciliares, reuniões de mães, centros de proteção infantil e escolas para mães (Freire, Leony, 2011; Fonseca, 1993). Na Polônia e na Iugoslávia, o Estado ficou responsável pelo cuidado tanto da maternidade como da infância. Na Alemanha, ações se expandiram a ponto de atingir cerca de 90\% dos lactentes do país (Fonseca, 1993).

No Uruguai, foram desenvolvidas alternativas próprias em que a política social apoiou as práticas de saúde pública, fornecendo subsídios para a criação do Ministério de Proteção à Criança - conselho consultivo organizador dos programas de bem-estar infantil - e para a instituição do Código del Niño, "que estendia os direitos da criança a saúde, bem-estar, educação, proteção legal e condições decentes de vida, e criava instituições especializadas para executar e supervisionar programas de proteção materno-infantil" (Birn, 2006, p.697). Cabe destacar o envolvimento e contribuição do país, na década de 1920, para a elaboração de uma agenda mundial de saúde infantil e a fundação do primeiro Instituto Internacional Americano de Protección a la Infancia, evidenciando-o como uma "rede exportadora de suas próprias inovações e abordagens para outros países da América Latina e para a comunidade internacional em larga escala" (Birn, 2006, p.680).

Na Argentina, o cuidado da infância ficou sob a órbita da Diretoria de Eugenia, criada em 1921. Com inspiração das propostas do Uruguai, implantou-se no Chile um Conselho Superior de Proteção à Infância e instituíram-se políticas de redução da mortalidade, especialmente voltadas para a desnutrição, com foco no pré-natal e no período de 
amamentação, expandindo o acompanhamento da criança até os 15 anos (Cárcamo et al., 2014; Lionetti, Miguez, 2010; Birn, 2006; Fonseca, 1993).

No Brasil, a partir da expansão das cidades e do comércio, entre o final do século XIX e início do século XX, observa-se o crescimento populacional e, com ele, uma maior complexidade da sociedade. A busca em garantir este modelo social em implantação, baseado na relação capital-trabalho, passa a exigir do Estado a inserção de novas tecnologias como forma de intervenção sobre os problemas sociais, e de saúde (Freire, 2009, 2014; Freitas, 2003; Reis, 2000; Fonseca, 1993; Gomes, Adorno, 1990).

E é nesse novo contexto de controle social resultante da necessidade de se investir sobre a força de trabalho que, assim como na Europa, a partir de 1920 o Estado brasileiro inicia propostas de mudanças, de caráter normativo, com destaque para os Serviços de Higiene Infantil, a regulamentação da licença à gestante e à puérpera, além da proibição do trabalho fabril para menores de 12 anos (Santos, Resegue, Puccini, 2012; Freire, Leony, 2011; Rosen, 1994; Gomes, Adorno, 1990).

Assim, pode-se identificar no início do século XX uma nova inflexão na concepção do "ser criança", quando se inicia o processo de constituição da criança como objeto de práticas com identidade própria, a partir da ampliação de ações institucionalizadas pelo Estado, de modo mais abrangente do que no século anterior. Nesse processo, as práticas de saúde ganham maior importância na determinação anterior da infância, quando a puericultura, inicialmente voltada somente para orientações das mães, estende sua abordagem educacional a outros campos de práticas, como a escola e a comunidade.

Seguindo o modelo higienista norte-americano que considerava a ignorância a principal causa da disseminação das doenças, inicia-se, a partir de 1924, em São Paulo, e em 1934, no Rio de Janeiro, a criação dos centros de saúde e a incorporação de ações educativas que tinham o objetivo de participação e responsabilização do indivíduo pela sua própria saúde e pela disseminação de ações e conhecimentos de higiene na comunidade (Freire, 2009, 2014; Mota, Schraiber, 2009; Zanolli, Merhy, 2001; Schraiber, Nemes, Mendes-Gonçalves, 2000; Mascarenhas, 1973).

Simultaneamente a esse contexto normativo de valorização da criança como futuro do país, observa-se a emergência de interesses sociais em conflito, representados pela manutenção e fortalecimento da função da mulher essencialmente como mãe e educadora do "futuro homem da nação", e, por outro lado, pelo novo papel da mulher trabalhadora que participa do mercado de trabalho e consome produtos industrializados para o cuidado do bebê e da casa, podendo transferir ao Estado o cuidado dessas crianças (Freire, 2009, 2014; Freitas, 2003).

A necessidade de construção de "trabalhadores sadios e vigorosos", junto à busca por controlar os elevados níveis de mortalidade infantil, compõe o cenário político-social que dá início no Brasil, a partir da década de 1930, a um processo de reformulação e expansão dos serviços relacionados ao cuidado com a criança, como parte das medidas do Estado. Até essa época, a maioria dos serviços responsáveis pela assistência à criança era composta por instituições privadas. A partir desse momento, observa-se uma aliança entre a medicina e o Estado em assumir o papel da família no cuidado das crianças, em busca de um objetivo comum - a criação de uma "nova raça" constituída por homens sadios e trabalhadores (Campos, 2007; Reis, 2000; Fonseca, 1993). 
Nesse sentido é que o Estado desencadeia uma série de ações, como a criação de uma Diretoria de Proteção à Maternidade e à Infância, em 1934, e a implantação nos centros de saúde para proteção médico-sanitária, tanto da gestante quanto da criança, estendendo assim "pela primeira vez a todo o País a atuação do governo federal nessa área", e assinalando a preocupação da nação em garantir a saúde e a educação da criança desde seu nascimento (Fonseca, 1993, p.101).

Essa responsabilidade do Estado em garantir os cuidados na infância ganha amplitude em 1937, quando a questão é incorporada à Constituição Federal. Em 1940, o decreto-lei n.2.024 torna-se um marco histórico para a atenção à saúde da criança, pois cria o Departamento Nacional da Criança (DNCr) e define como sua responsabilidade a organização das Políticas de Saúde à Criança em nível nacional, para serviços tanto públicos quanto privados (Brasil, 2011; Reis, 2000; Iyda, 1994; Fonseca, 1993).

Como parte das atribuições do DNCr, era prevista a realização de inquéritos para estudar e, posteriormente, divulgar para a opinião pública orientações sobre o problema social relacionado à maternidade, infância e adolescência, além de estimular e orientar a organização dos estabelecimentos destinados a esse público. Cabia, ainda, fiscalizar todas as ações em âmbito nacional, promover a cooperação da União com todos os estados e serviços privados, visando garantir a expansão e manutenção dos serviços destinados à proteção desse grupo (Brasil, 2011).

O referido decreto estabelece, ainda, a descentralização das ações para os Departamentos Estaduais da Criança e para os municípios, com a preocupação em garantir uma maior aproximação com as diferentes realidades e um olhar diferenciado para esse grupo populacional tão heterogêneo no país (Iyda, 1994).

Essas ações demonstram a preocupação do Estado brasileiro com a assistência materno-infantil e a reorganização dos serviços de saúde, com ampla incorporação das ações propostas pela puericultura de caráter educativo e cuidado dos sadios. As práticas de saúde dessa fase mantinham o enfoque normativo de épocas anteriores, como as propostas higienistas para as famílias e as ações campanhistas, com a atenção individual como instrumento para atingir o coletivo (Lage, Rosa, 2011; Mendes-Gonçalves, 1994; Gomes, Adorno, 1990).

Acompanhando essa transformação da medicina, a psiquiatria nessa época reforça a forte influência da prática médica como ferramenta de intervenção preventiva na constituição de uma população (de trabalhadores) sadia, e que, devido à facilidade de "moldá-la", encontra na criança em idade pré-escolar seu principal objeto de atuação. Consolida-se dessa forma a "psicopediatria", que no Brasil encontrou nas escolas sua principal área de atuação, seja ela de caráter preventivo ou assistencial, como no caso da proposta das "escolas-hospitais", responsáveis por cuidar "do corpo e da alma" (Reis, 2000; Fonseca, 1993).

No sentido de "organização das cidades", porém tendo como objeto de ação a criança em vez da mãe, destaca-se a Liga Brasileira de Higiene Mental (LBHM), que buscava identificar os "desviantes" nas escolas públicas, além de orientar a atuação da professora que, exercendo autoridade junto ao ambiente escolar e comunitário, deveria estudar as publicações sobre puericultura para repassar os conhecimentos aos alunos (Freire, 2009, 2014; Freitas, 2003; Pereira, 1999). 
As tensões entre distintos projetos sociais envolvendo crianças e mães também podem ser observadas nas ações do campo da saúde em relação às orientações quanto à amamentação. Os postos de puericultura propostos pelo DNCr, em coerência com o ideário do Estado Novo de cuidar dos "futuros trabalhadores" e desenvolver uma "raça eugênica", coordenados por médicos não especialistas, apresentavam como principal função organizar ações preventivas e dirigir o lactário, promovendo extração e redistribuição do leite materno (Reis, 2000; Pereira, 1999, Fonseca, 1993). Além disso, propunham reforçar o estímulo para a "amamentação ao peito - considerado [há vários anos] o mais perfeito alimento para o indivíduo na primeira infância" (Pereira, 1999, p.172). Simultaneamente a essas orientações, observa-se uma crescente divulgação publicitária das supostas vantagens do uso do leite em pó "substituindo com maior benefício, caso o leite materno 'faltasse', mensagem difundida ao longo de muitas décadas, proporcionando facilidade do preparo, conservação das propriedades do leite fresco e digestibilidade do produto" em relação ao leite materno (Bosi, Machado, 2005, p.6; destaque no original).

Destaca-se que a disseminação do leite em pó no Brasil já ocorria desde décadas anteriores, mas nos anos de 1930 ganhou impulso, quando passou a ser fabricado pela Indústria Nacional de Alimentos Infantis, passando "a ser reforçada a importância de generalizar a utilização das fórmulas para todas as crianças, como alimento opcional" (Bosi, Machado, 2005, p.6).

No estado de São Paulo, em 1945, teve início a realização da Semana da Criança e Campanha da Redenção da Criança, responsáveis por grande mobilização da população para colaborar com os serviços de assistência materno-infantil, nos centros de saúde e nos postos de puericultura (Iyda, 1994; Mendes-Gonçalves, 1991; Mascarenhas, 1973).

Em relação às inflexões das tecnologias voltadas para as crianças, observa-se a educação sanitária como prática de atenção diretamente dirigida ao atendimento infantil. A prática da educação no atendimento clínico traz para o individual parte da responsabilidade sobre o coletivo, marcando uma nova inflexão tecnológica caracterizada por recomendações que, em sua essência, desconsideravam os saberes das mães, prescrevendo normas e regras de como melhor deveriam cuidar de seus filhos.

Nota-se que é a partir da década de 1950 que a saúde da criança no país passa a ser favorecida pela legislação e a se tornar objeto mais sistemático das ações do Estado. Nesse momento, há uma nova concepção do "ser criança", que passa a ser caracterizada como objeto de programas de normatização, como a lei n.1.091 de 1951 da Secretaria da Fazenda, que estabelece o repasse de dinheiro para a instalação de postos de puericultura e aquisição de veículos destinados à assistência materno-infantil; a incorporação do DNCr ao Ministério da Saúde, em 1953; e a proposta do Programa Nacional de Merenda Escolar, em 1954, como medida de suplementação alimentar dirigida a escolares carentes (Brasil, 2011; Perez, Passone, 2010; Iyda, 1994).

Observa-se que à medida que os direitos da infância vão sendo legitimados por meio de diferentes políticas de proteção social, a concepção do "ser criança" avança em direção a um maior reconhecimento de cidadania. No esteio da Declaração Universal dos Direitos Humanos, a Organização das Nações Unidas (ONU) aprova, em 1959, a Declaração Universal 
dos Direitos da Criança. Além de direitos sociais, como identidade e acesso à educação, ela traz um item especifico que localiza a saúde como direito previdenciário:

A criança gozará os benefícios da previdência social. Terá direito a crescer e criar-se com saúde; para isto, tanto à criança como à mãe, serão proporcionados cuidados e proteções especiais, inclusive adequados cuidados pré e pós-natais. A criança terá direito a alimentação, recreação e assistência médica adequadas (ONU, 20 nov. 1959, Princípio 4).

Esse documento e os valores por ele propostos, assim como sua incorporação no Brasil, pelo Ministério da Saúde, influenciaram ações em instituições como as escolas (Freire, Leony, 2011; Perez, Passone, 2010; Zanolli, Merhy, 2001).

Nos anos de 1960, ocorreu no Brasil, de um modo geral, uma acentuada desaceleração do desenvolvimento das práticas sanitárias, caracterizada por uma "estagnação" nas ações de saúde pública, mantendo-se apenas aquelas dirigidas a alguns grupos prioritários e à manutenção de campanhas sanitárias, tais como ações do Programa de Imunização (1964) e a imunização em massa contra doenças transmissíveis (1968) (Zanolli, Merhy, 2001; Iyda, 1994; Mendes-Gonçalves, 1991; Schraiber, 1990; Mascarenhas, 1973).

Por outro lado, no estado de São Paulo, ocorreu uma grande expansão dos centros de saúde e postos de puericultura, que aumentaram de oito na capital e 248 no interior em 1955, para 129 na capital e 427 no interior, em 1965. Durante esse período, pode-se identificar, nos centros de saúde, a articulação entre as práticas coletivas e individuais, com medidas de cuidado direcionadas aos sujeitos sem perder o caráter coletivo, visto que as ações individuais eram priorizadas conforme seu significado epidemiológico e potencial impacto sobre a saúde da população-alvo (Schraiber, 1990; Castanheira, 1996).

Em nível nacional, é apenas na década de 1970 que a assistência à saúde da criança volta a ter destaque, alimentada pelas preocupações de expansão do atendimento médico voltado para a mão de obra urbano-industrial. Ela se desenvolveu como parte das tentativas de implantar políticas sociais que favorecessem a economia do país (Santos, Resegue, Puccini, 2012; Gomes, Adorno, 1990).

O decreto n.66.623, de maio de 1970, criou a Coordenação de Proteção Materno-Infantil vinculada à Secretaria de Assistência Médica do Ministério da Saúde, com a função de "planejar, orientar, coordenar, controlar, auxiliar e fiscalizar as atividades de proteção à maternidade, à infância e à adolescência" (Brasil, 2011, p.12).

Evidencia-se nos anos 1970 a valorização da criança como ser em desenvolvimento, reforçando a importância do acompanhamento do crescimento e desenvolvimento saudável, com o estímulo à implantação de creches como estratégia de atenção integral para menores de cinco anos. Ao mesmo tempo, estimulou-se a incorporação de novas tecnologias de saúde ao atendimento de puericultura e às ações já reconhecidas de prevenção de doenças infectocontagiosas.

Em 1975, foi criado o Programa Nacional de Saúde Materno-infantil que tinha como objetivo central contribuir para a redução da morbidade e mortalidade materna e infantil. Para isso, adotava como diretriz principal o aumento da cobertura do atendimento maternoinfantil e a suplementação alimentar (Schraiber, Nemes, Mendes-Gonçalves, 2000; Iyda, 1994; Gomes, Adorno, 1990; Mascarenhas, 1973). 
No estado de São Paulo, até 1976, a distribuição de leite pelos centros de saúde se dava a partir de avaliação socioeconômica (mãe solteira sem amparo; família numerosa em má situação financeira; prematuro ou gêmeo) e só ingressava uma nova criança quando outra tinha alta. A introdução da suplementação alimentar para todas as crianças inscritas até um ano de idade modificou esses critérios, passando-se a distribuir latas de leite em pó para todos os menores de um ano, independente de quaisquer condições, "em 77, tinha $70 \%$ dos menores de um ano residentes no estado [São Paulo] inscritos no programa [de saúde da criança] dos quais a grande maioria recebia suplementação alimentar" (Schraiber, 1990, p.94).

Esse processo fez parte da expansão da cobertura à saúde da criança, com a aplicação de práticas de atenção individual sistematizadas em normas para atendimentos médicos e de enfermagem, que previam a realização de no mínimo quatro atendimentos rotineiros para os menores de um ano, com abordagem padronizada de orientações alimentares, como o preparo de mamadeiras (Zanolli, Merhy, 2001).

Em todo o país, ainda na década de 1970, o acompanhamento do crescimento e desenvolvimento infantil passou a ser registrado no cartão da criança, como forma de exercer um maior controle sobre a saúde, recebendo uma ampla divulgação para sua utilização. O Programa de Imunização, já desenvolvido no estado de São Paulo, ganhou abrangência nacional. A vacinação começou a ser ministrada desde a primeira semana de vida, com complementação em anos posteriores utilizando-se esquemas vacinais por idade - estratégia mantida até os dias atuais (Brasil, 2011; Iyda, 1994).

Nesse cenário de expansão dos serviços e de ampliação das ações, se destaca o incentivo financeiro para a capacitação das equipes de saúde, estímulo ao alojamento conjunto de mãe e bebê nas maternidades, e controle das infecções respiratórias agudas, além da terapia de reidratação oral (Brasil, 2011; Iyda, 1994; Gomes, Adorno, 1990).

A partir de 1981, são observadas mudanças não somente na ampliação e diversidade das ações, mas, também, na criação de programas separados para a Assistência Integral à Saúde da Criança e à Saúde da Mulher, favorecendo o apoio e a ampliação de incentivos financeiros, desenvolvimento de recursos humanos, avaliação e acompanhamento de pesquisas, e trabalhos voltados para a educação em saúde. Além disso, houve a formação do Comitê de Saúde Perinatal e a formulação da Política Nacional de Incentivo ao Aleitamento Materno. Apesar de existirem, desde 1969, dispositivos legais que vinculavam os centros de saúde aos postos de puericultura, foi a partir de 1986 que ocorreu a integração desses serviços na prática (Brasil, 2011; Castanheira, 1996; Mendes-Gonçalves, 1994).

Os anos 1980 caracterizaram-se pelas mobilizações de caráter político e ideológico, bem representadas no campo da saúde pelo movimento da Reforma Sanitária. Elas favoreceram mudanças que contribuíram para forjar a conotação mais contemporânea do termo "criança", reportando-se à expressão "infante-criança" como aquele que está sendo criado, com voz e participação, que proporciona a troca entre as gerações, porém, ainda sem ser reconhecido e respeitado como protagonista (Paim et al., 2011; Schultz, Barros, 2011; Victora et al., 2011).

Nesse período, as práticas de atenção à saúde da criança nos centros de saúde mantiveram como proposição o acompanhamento das crianças saudáveis e a priorização dos problemas 
epidemiologicamente importantes. No entanto, a introdução da assistência médica individual, ou seja, do atendimento aos doentes, trouxe para o interior dos serviços de saúde pública as tensões entre o cuidado individual e o coletivo (Mendes-Gonçalves, 1991; Schraiber, 1990).

A incorporação da atenção individual propicia a inversão da racionalidade da atenção realizada, secundarizando a perspectiva epidemiológica. A valorização das demandas individuais de cuidado tende a enfraquecer a conexão com as necessidades de saúde postas para a comunidade (Schraiber, 1990). Por outro lado, a possibilidade de reconhecimento das demandas individuais coloca em cena a necessidade de se olhar para cada sujeito em sua individualidade, valor que ganha expressão social nesse período e que passa a ser posto como questão para as práticas de saúde.

A Constituição Federal de 1988 representou um divisor de águas no país e registra o amadurecimento de um modelo que reconhece o social: implantou um Sistema Nacional de Saúde (SUS) que unificou os sistemas de financiamento e descentralizou sua gestão, além de instituir os princípios de universalidade, equidade e integralidade e de introduzir mudanças na produção e distribuição dos serviços. Dessa forma, o cidadão foi redefinido como sujeito de direitos. O conceito de "saúde", por sua vez, passou a englobar aspectos multidimensionais da vida humana. Nessa perspectiva, a criança passou a ser entendida como sujeito de direitos, e com prioridade em relação a outros segmentos sociais, cabendo à família, à sociedade e ao Estado a responsabilidade por garantir esses direitos (Brasil, 2011; Paim et al., 2011; Figueiredo, Mello, 2007; Freitas, 2003).

De fato, a transição de um modelo programático de base epidemiológica para um de atenção mais integral, dedicado a responder à diversidade e à especificidade das necessidades individuais, tendeu a conferir protagonismo à atenção individual em detrimento da dimensão coletiva. No cotidiano dos serviços, essas duas dimensões permaneceram desarticuladas, desobedecendo a proposta de algumas vertentes, como a ação programática e a vigilância da saúde (Schraiber, Nemes, Mendes-Gonçalves, 2000; Paim, 1992). Nos anos de 1980, o modelo assistencial que se tornou hegemônico nos serviços públicos centrou-se na atenção médica individual, nominado como "consultação" ou "modelo médico-assistencial privatista" (Teixeira, Solla, 2006).

A reformulação do sistema de saúde, com a criação do SUS, implementou a extensão da rede assistencial, além de impulsionar o desenvolvimento de novos campos de reflexões críticas, como nas áreas de saúde mental, abrindo espaço para a implantação de novas práticas (Paim et al., 2011; Mendes-Gonçalves, 1991).

Essas mudanças, ao introduzir a proposição de ações baseadas no planejamento a partir da análise das condições sanitárias e epidemiológicas e da incorporação dos princípios éticos e organizacionais do SUS, que apresentam novos valores ao "ser criança", passaram a alimentar o desenvolvimento de novas tecnologias de saúde coerentes com tal ideário, demarcando uma nova fase tanto em relação ao "ser criança" quanto às práticas de saúde a elas dirigidas (Figueiredo, Mello, 2007; Teixeira, Solla, 2006).

Foi a partir desse novo contexto que, depois de 1990, a concepção do "ser criança" ou de "infância" ganhou uma nova inflexão que lhe conferiu vez e voz diante das decisões políticas vigentes, caracterizando-a como objeto de práticas e sujeito social portador de direitos. 
A doutrina de proteção integral da criança e do adolescente promulgada no Estatuto da Criança e do Adolescente (ECA) (Brasil, 1990) expressa bem esse processo. A concepção de "sujeito de direitos" remete também a "sujeito de deveres", marcando um importante diferencial no "ser criança", que passa formalmente a ter direitos e responsabilidades como sujeito social (Schultz, Barros, 2011; Frota et al., 2010; Freitas, 2003).

Mudanças nesse sentido também foram observadas nas ações de saúde, para as quais as diretrizes presentes no SUS definiram novos arranjos tecnológicos de atenção à saúde e novas estratégias organizacionais. A implantação do Programa de Saúde da Família (PSF) e a descentralização, por meio da municipalização dos serviços de APS, ampliaram o acesso em todas as regiões do país, especialmente nos bolsões antes desassistidos. A maior facilidade de acesso às intervenções de saúde dirigidas às mães e às crianças permitiu que o país ampliasse a cobertura desse segmento, reduzindo notavelmente as desigualdades regionais, o que foi expresso na melhoria dos indicadores de saúde (Victora et al., 2011; WHO, 2008).

Nesse novo cenário, a assistência à criança buscou contemplá-la em seu processo de desenvolvimento e crescimento. Também incluiu ações de promoção da saúde focadas em segmentos de maior vulnerabilidade social, para além do cuidado das demandas e necessidades individuais.

Vale assinalar que muitas ações já implantadas em períodos anteriores, apesar de assumir novos significados tecnológicos, se mantêm até os dias atuais, como, por exemplo, as campanhas de vacinação, que mantêm seu caráter de estratégia de base populacional, mas que, no entanto, à medida que incorporaram novas bases técnico-científicas, passando a responder a outras necessidades sociais de saúde, apresentam-se como ações distintas das anteriores.

A emergência de projetos intersetoriais aponta para uma nova compreensão sobre a criança, cujo cuidado integral precisa envolver outros setores, além de dar nova dimensão aos próprios serviços de saúde. Nessa direção, foram propostos projetos como o Carteiro Amigo, os Bombeiros da Vida, Biblioteca Viva, a Campanha Nacional de Registro de Nascimento e o Hospital Amigo da Criança (Brasil, 2011; Frota et al., 2010; Figueiredo, Mello, 2007).

Algumas medidas merecem destaque. A partir de 2000, incorporou-se às ações de saúde o conceito de humanização e integralidade da atenção à criança, inicialmente por meio do Programa de Humanização no Pré-natal e Nascimento (PHPN), seguido por documento que acrescenta às ações a preocupação com a prevenção de acidentes e violência na infância Atenção Integrada às Doenças Prevalentes na Infância (Aidpi). Essa tendência se fortaleceu com a publicação da Agenda de Compromissos para a Saúde Integral da Criança e Redução da Mortalidade Infantil e com a ampliação da faixa etária controlada pela Caderneta de Saúde da Criança, que em 2005 passou a ser obrigatória para crianças até dez anos de idade (Brasil, 2011; Figueiredo, Mello, 2007).

Nessa mesma direção, em 2010, o Plano Nacional para a Primeira Infância (PNPI) reforçou a prioridade de redução da mortalidade infantil enfatizando o respeito aos direitos da criança em todos os seus aspectos: biológico, afetivo, psíquico e social. O PNPI prevê o envolvimento de diferentes atores para o alcance desses objetivos - como a saúde, a educação e a assistência social, além da comunidade (Brasil, 2011; Figueiredo, Mello, 2007). 
Atualmente, seguindo as recomendações da Organização Mundial da Saúde (OMS), foi definida a Estratégia Brasileirinhas e Brasileirinhos Saudáveis, que busca fortalecer a articulação das ações voltadas para para a saúde da mulher e da criança até seis anos de idade, com base nos determinantes sociais da saúde (Brasil, 2010; WHO, 2008). A promulgação, em 2015, da portaria n.1.130, que institui a Pnaisc (Brasil, 5 ago. 2015), representa o reconhecimento da importância de ações de atenção à saúde da criança mais sistematizadas. A Pnaisc prevê a integralidade da atenção tomando como base os serviços de APS e organiza suas ações em sete eixos de cuidado: (1) atenção humanizada e qualificada à gestação, ao parto, ao nascimento e ao recém-nascido; (2) aleitamento materno e alimentação complementar saudável; (3) promoção e acompanhamento do crescimento e do desenvolvimento integral; (4) atenção integral a crianças com agravos prevalentes na infância e com doenças crônicas; (5) atenção integral a crianças em situação de violências, prevenção de acidentes e promoção da cultura de paz; (6) atenção à saúde de crianças com deficiência ou em situações específicas e de vulnerabilidade; e (7) vigilância e prevenção do óbito infantil, fetal e materno (Brasil, 5 ago. 2015).

Conforme apontado por essas iniciativas, entre os desafios para os serviços de saúde, além da atuação intersetorial e interdisciplinar, está a incorporação de dimensões socioculturais às tecnologias de cuidado, que estão presentes nas necessidades de atenção individualizadas de cada um. Nessa direção, corroboram diversas proposições, com sentidos e racionalidades complementares. A proposta de desenvolvimento de projetos terapêuticos singulares, a partir do exercício de uma Clínica Ampliada e Compartilhada (Campos, Guerrero, 2010), em sua radicalidade de individuação do caso, contempla a interlocução entre necessidades individuais e coletivas. Ou seja, desenvolver ações baseadas no vínculo e na corresponsabilidade, com adequação das terapêuticas a cada caso, ao mesmo tempo exige um olhar sobre o contexto sociocultural, o que requer responsabilização das equipes de saúde e o desenvolvimento de ações integradas entre as diferentes práticas sociais que nele atuam. Essas proposições são coerentes com o processo social de redefinição do "ser criança" como sujeito de direitos, pois, ao tempo que resgata a individualidade dos sujeitos, articula as ações aos determinantes sociais de saúde. Entretanto, esse processo tem encontrado muitos obstáculos a seu desenvolvimento.

São ainda isoladas as práticas de educação em saúde definidas de modo articulado com a comunidade, tais como estratégias desenvolvidas em grupos e visitas domiciliares que procuram recolocar o conceito de risco no coletivo e favorecer o empoderamento por meio da integração do saber popular ao técnico. Ao contrário, prevalecem ações organizadas no formato de palestras ou campanhas pontuais, cuja efetividade se coloca no nível da propaganda e mera difusão dos temas abordados, muitas vezes incluindo mensagens subliminares opostas ao apresentado (Oliveira, Veríssimo, 2015; Sanine, 2014).

Estudos apontam que as práticas de atenção à saúde da criança realizadas nos serviços de APS mantêm-se muito distantes das proposições apresentadas. Tal distância também se evidencia em relação aos temas abordados nas ações programadas para o atendimento infantil: há o predomínio de temas tradicionais, como aleitamento materno e desnutrição, secundarizando-se temas emergentes como trabalho infantil, criminalidade infantil, entre outros já legitimados nas políticas públicas (Sanine, 2014). 
Em que pese as transformações ambicionadas pelas diferentes proposições políticas, tanto no campo teórico quanto nas diretrizes e planos de atuação, pode-se dizer que as mudanças observadas no cotidiano dos serviços ainda são incipientes, incompletas ou isoladas, não caracterizando a maioria dos serviços de APS, apesar de algumas experiências exitosas (Frota et al., 2010; Victora et al., 2011).

Nota-se, ainda, nos tempos atuais, a reprodução de um modelo centrado na demanda imediata e no risco presumido para cada criança, segundo o diagnóstico clínico, em vez de se basear na singularidade ou na conexão do caso com o coletivo social no qual se insere (Sanine, 2014; Zanolli, Merhy, 2001). Observa-se a tendência em reforçar o modelo que se quer superar, de base biologicista, centrado no trabalho médico e na doença, com prescrições normativas, no qual a criança permanece como objeto passivo de programas pulverizados.

Em outras palavras, as práticas exercidas atualmente nos serviços de APS não avançam na integralidade do cuidado, segundo a concepção do "ser criança" como sujeito de direitos, com reconhecimento e respeito ao universo infantil, que deve ser diferenciado do pequeno adulto, futuro trabalhador.

\section{Considerações finais}

O texto procurou caracterizar as inter-relações entre as transformações na construção social do "ser criança" e as diferentes proposições políticas e tecnológicas de atenção à saúde da criança no Brasil. A análise permitiu identificar três diferentes concepções do significado da criança, demarcando um processo que vai da criança como "matriz de mão de obra", passando pela criança como "objeto de programas que normatizam a infância", mas também o corpo sadio e doente, até sua instituição como "objeto de práticas e sujeito social portador de direitos".

Procurou-se evidenciar que as práticas de saúde, como práticas sociais, são pautadas e participam da definição social do "ser criança", e que as políticas públicas, associadas aos diferentes contextos sociais nos quais estão inseridas, podem ser indutoras de mudanças. As inflexões entre as distintas concepções de criança e as transformações e/ou os marcos de inflexões tecnológicas da saúde estão relacionadas, ainda que não guardem correspondência cronológica imediata.

As tecnologias dirigidas à criança na APS no Brasil são similares às observadas em outros países. Subsiste o interesse político e econômico na concepção do "bem-estar" social da população, na qual os serviços de saúde participam da criação das condições indispensáveis ao desenvolvimento da vida política, social e econômica e sua organização. Assim como em outras partes do mundo ocidental, a finalidade não é só manter e reproduzir a força de trabalho como base material da produção, mas também os valores sociais que fundamentam a sociedade capitalista contemporânea.

O texto apresentado teve por finalidade contribuir com o debate sobre as práticas de saúde dirigidas à criança, de modo a fornecer elementos para um olhar crítico sobre quais necessidades de saúde vêm sendo atualmente reproduzidas. Coloca-nos diante do desafio de desenvolver tecnologias de cuidado que fortaleçam a criança como sujeito de direitos sociais e que se contraponham à inversão destes como direitos ao consumo de diagnósticos, 
medicamentos e exames, que adoecem a infância em vez de ampliar seus direitos a uma vida saudável.

As tensões apontadas entre os esforços em implementar políticas de saúde que redefinem a criança como sujeito social e a persistência de "velhas" práticas de saúde reforçam o questionamento se o modelo, ainda hegemônico ao reproduzir concepções socialmente ultrapassadas sobre a criança, não está incorporando e retraduzindo as novas concepções a partir de uma racionalidade tecnológica que acaba por manter a abordagem da criança limitada aos cuidados do futuro adulto e, nesse sentido, tratando-a como um adulto em miniatura, só que agora socialmente valorizado por sua capacidade de consumo de tecnologias de saúde.

\section{AGRADECIMENTOS}

Agradecemos aos amigos professor doutor Valdemar Pereira de Pinho e professora doutora Catia Fonseca pelo valioso incentivo e motivação para a realização deste trabalho.

\section{REFERÊNCIAS}

ARIÈS, Philippe.

História social da criança e da família. Tradução Dora Flaksman. Rio de Janeiro: Livros Técnicos e Científicos. 1981.

BIRN, Anne-Emanuelle.

O nexo nacional-internacional na saúde pública: o Uruguai e a circulação das políticas e ideologias de saúde infantil, 1890-1940. História, Ciências, Saúde-Manguinhos, v.13, n.3, p.675708. 2006.

BOSI, Maria Lúcia M.; MACHADO, Márcia T. Amamentação: um resgate histórico. Cadernos ESP, v.1, n.1, p.1-9. 2005.

BRASIL.

Ministério da Saúde. Portaria n.1.130, de 5 de agosto de 2015. Institui a Política Nacional de Atenção Integral à Saúde da Criança (PNAISC) no âmbito do Sistema Único de Saúde (SUS). Disponível em: http://bvsms.saude.gov.br/bvs/ saudelegis/gm/2015/prt1130_05_08_2015.html. Acesso em: 14 nov. 2017. 5 ago. 2015.

BRASIL.

Ministério da Saúde. Secretaria de Atenção à Saúde. Departamento de Atenção Básica. Política Nacional de Atenção Básica. Brasília: Ministério da Saúde. 2012.

BRASIL.

Área Técnica de Saúde da Criança e Aleitamento Materno. Gestões e gestores de políticas públicas de atenção à saúde da criança: 70 anos de história. Brasília: Ministério da Saúde. 2011.

BRASIL.

Ministério da Saúde. Departamento de Ações Programáticas e Estratégicas em Saúde.
O futuro hoje: estratégia brasileirinhas e brasileirinhos saudáveis: primeiros passos para o desenvolvimento nacional. Brasília: Ministério da Saúde. 2010.

BRASIL.

Lei n.8.069, de 13 de julho de 1990. Dispõe sobre o Estatuto da Criança e do Adolescente e dá outras providências. Disponível em: http:// www.planalto.gov.br/ccivil_03/leis/L8069.htm. Acesso em: 14 nov. 2017. 13 jul. 1990.

CAMPOS, Carlos Eduardo A.

As origens da rede de serviços de atenção básica no Brasil. História, Ciências, Saúde - Manguinhos, v.14, n.3, p.877-906. 2007.

CAMPOS, Gastão Wagner S.; GUERRERO, André Vinicius P. (Org.).

Manual de práticas da atenção básica: saúde ampliada e compartilhada. São Paulo: Hucitec. 2010.

CÁRCAMO, Rodrigo A. et al.

From foundling homes to day care: a historical review of childcare in Chile. Cadernos de Saúde Pública, n.30, v.3, p.461-471. 2014.

CASTANHEIRA, Elen Rose L.

Gerência do trabalho em saúde: desenvolvimento histórico da administração em saúde nos serviços públicos do estado de São Paulo. Dissertação (Mestrado) - Faculdade de Medicina, Universidade de São Paulo, São Paulo. 1996.

DALMASO, Ana Silvia W.; SCHRAIBER, Lilia B. O trabalho em saúde e a organização da prática. São Paulo: Cefor. 1992.

DEL CIAMPO, Luiz Antonio et al.

O Programa de Saúde da Família e a 
puericultura. Ciência e Saúde Coletiva, v.11 n.3, p.739-743. 2006.

DEL PRIORI, Mary (Org.).

História da criança no Brasil. São Paulo: Contexto. 1991.

DONNANGELO, Maria Cecília F.

Medicina e sociedade. São Paulo: Pioneira. 1975.

FIGUEIREDO, Glória Lúcia A., MELLO, Débora F. Atenção à saúde da criança no Brasil: aspectos da vulnerabilidade programática e dos direitos humanos. Revista Latino-americana de Enfermagem, v.15, n.6, p.1171-1176. 2007.

FONSECA, Cristina M.O.

A saúde da criança na política social do primeiro governo Vargas. Physis, v.3, n.2, p.97-116. 1993.

FOUCAULT, Michel.

Microfísica do poder. Tradução Roberto Machado. Rio de Janeiro: Graal. 1982.

FREIRE, Maria Martha Luna.

A puericultura em revista. Physis, v.24, n.3, p.973-993. 2014.

FREIRE, Maria Martha Luna.

Mulheres, mães e médicos: discurso maternalista no Brasil. Rio de Janeiro: FGV Editora. 2009.

FREIRE, Maria Martha Luna; LEONY, Vinicius S. A caridade científica: Moncorvo Filho e o Instituto de Proteção e Assistência à Infância do Rio de Janeiro, 1899-1930. História, Ciências, Saúde-Manguinhos, v.18, supl.1, p.199-225. 2011.

FREITAS, Marcos Cezar (Org.).

História social da infância no Brasil. São Paulo: Cortez. 2003.

FROTA, Mirna A. et al.

Reflexão sobre políticas públicas e estratégias na saúde integral da criança. Enfermagem em Foco, v.1, n.3, p.129-132. 2010.

GOMES, Fabíola Z.; ADORNO, Rubens C.F. Crescimento e desenvolvimento na prática dos serviços de saúde: revisão histórica do conceito de criança. Revista de Saúde Pública, v.24, n.3, p.204-211. 1990.

IYDA, Massako.

Cem anos de saúde pública: a cidadania negada. São Paulo: Unesp. 1994.

LAGE, Michelle T.; ROSA, Marco André C. Evolução da infância no Brasil: do anonimato ao consumismo. Revista Eletrônica de Educação, v.4, n.8. Disponível em: http://www.unifil.br/ portal/images/pdf/documentos/revistas/revistaeletronica/educacao/jan-jun-2011.pdf. Acesso em: 16 nov. 2017. 2011.
LIONETTI, Lucía; MIGUEZ, Daniel.

Las infancias en la historia Argentina: intersecciones entre prácticas, discursos e instituciones, 1890-1960. Rosario: Prohistoria. 2010.

MASCARENHAS, Rodolfo S.

História da saúde pública no estado de São Paulo. Revista de Saúde Pública, n.7, p.433-446. 1973.

MENDES-GONÇALVES, Ricardo Bruno. Tecnologia e organização social das práticas de saúde: características tecnológicas do processo de trabalho na rede estadual de centros de saúde de São Paulo. São Paulo: Hucitec; Abrasco. 1994.

MENDES-GONÇALVES, Ricardo Bruno. Práticas de saúde: processos de trabalhos e necessidades. São Paulo: Cefor. 1992.

MENDES-GONÇALVES, Ricardo Bruno. A saúde no Brasil, algumas características do processo histórico nos anos 80. São Paulo em Perspectiva, v.5, n.1, p.99-106. 1991.

MENDES-GONÇALVES, Ricardo Bruno; SCHRAIBER, Lilia B.; NEMES, Maria Inês B. Seis teses sobre a ação programática em saúde. São Paulo: Hucitec. 1990.

MINAYO, Maria Cecília.

Anthropological approach to the evaluation of social policies. Revista de Saúde Pública, v.25, n.3, p.233-238. 1991.

MOTA, André; SCHRAIBER, Lilia B. (Org.). Infância e saúde: perspectivas históricas. São Paulo: Hucitec; Fapesp. 2009.

OLIVEIRA, Vanessa B.C.A.; VERÍSSIMO, Maria L.Ó.R.

Assistência à saúde da criança segundo suas famílias: comparação entre modelos de atenção primária. Revista da Escola de Enfermagem da USP, v.49, n.1, p.30-36. 2015.

ONU.

Organização das Nações Unidas. Declaração Universal dos Direitos das Crianças, de 20 de novembro de 1959. Disponível em: http://www. dhnet.org.br/direitos/sip/onu/c_a/lex41.htm. Acesso em: 16 nov. 2017. 20 nov. 1959.

PAIM, Jairnilson S.

A reforma sanitária e a municipalização. Saúde e Sociedade, v.1, n.2, p.29-47. 1992.

PAIM, Jairnilson S. et al.

The Brazilian health system: history, advances, and challenges. The Lancet, v.377, n.9779, p.1778-1797. 2011. 
PEREIRA, André Ricardo.

A criança no Estado Novo: uma leitura na longa duração. Revista Brasileira de História, v.19, n.38, p.165-198. 1999.

PEREZ, José Roberto R.; PASSONE, Eric F. Políticas sociais de atendimento às crianças e aos adolescentes no Brasil. Cadernos de Pesquisa, v.40, n.140, p.649-673. 2010.

REIS, José Roberto F.

"De pequenino é que se torce o pepino": a infância nos programas eugênicos da Liga Brasileira de Higiene Mental. História, Ciências, Saúde-Manguinhos, v.7, n.1, p.135-157. 2000.

ROSEN, George.

Uma história da saúde pública. São Paulo: Unesp; Rio de Janeiro: Hucitec; Abrasco. 1994.

SANINE, Patricia R.

Avaliação da atenção à saúde da criança em unidades de saúde no estado de São Paulo. Dissertação (Mestrado) - Faculdade de Medicina de Botucatu, Universidade Estadual Paulista, Botucatu. 2014.

SANTANA, Judith S.S.; ARAÚJO, Maria Marta L. Inespecificidade e invisibilidade da saúde da criança no Brasil colônia: fragmentos de um discurso português. Revista Enfermagem Uerj, n.17, v.3, p.326-331. 2009.

SANTOS, Renata C.K.; RESEGUE, Rosa; PUCCINI, Rosana F.

Childcare and children's healthcare: historical factors and challenges. Journal of Human Growth and Development, v.22, n.2, p.160-165. 2012.
SCHRAIBER, Lilia B. (Org.).

Programação em saúde hoje. São Paulo: Hucitec. 1990.

SCHRAIBER, Lilia B.; NEMES, Maria Inês B.; MENDES-GONÇALVES, Ricardo Bruno (Org.). Saúde do adulto: programas e ações na unidade básica. São Paulo: Hucitec. p.29-47. 2000.

SCHULTZ, Elisa S.; BARROS, Solange M. A concepção de infância ao longo da história no Brasil contemporâneo. Revista de Ciências Jurídicas, v.3, n.2, p.137-147. 2011.

TEIXEIRA, Carmen F.; SOLLA, Jorge P. Modelo de atenção à saúde: vigilância e saúde da família. Salvador: Edufba. 2006.

VICTORA, Cesar G. et al. Maternal and child health in Brazil: progress and challenges. The Lancet, v.377, n.9780, p.1863-1876. 2011.

WHO.

World Health Organization. The World Health Report 2008: primary health care, now more than ever. Geneva: WHO. 2008.

WOLFE, Ingrid et al.

Health services for children in Western Europe. The Lancet, v.381, p.1224-1234. 2013.

ZANOLLI, Maria de Lurdes; MERHY, Emerson E. A pediatria social e as suas apostas reformistas. Cadernos de Saúde Pública, n.17, v.4, p.977-987. 2001.

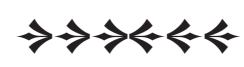

